Iberian Journal of the History of Economic Thought

ISSN-e 2386-5768

\title{
De la violencia colonial a las nuevas violencias: El pensamiento de la circulación y la travesía de Achille Mbembe
}

Fernando López Castellano ${ }^{1}$

\author{
“ ¿No tengo acaso \\ un abuelo nocturno \\ con una gran marca negra \\ (más negra todavía que la piel) \\ una gran marca hecha de un latigazo?"
}

Con estos emotivos versos, el poeta cubano Nicolás Guillén indaga en el apellido "ahogado en tinta de notario" de su antepasado; el apellido "sangriento y capturado", que pasó sobre el mar entre cadenas. Guillén expresa en tono poético la impresión que dejara escrita A. de Tocqueville en su Democracia en América: "El negro de Estados Unidos perdió inclusive hasta el recuerdo de su país; ya no comprende más la lengua que hablaban sus padres; ha abjurado de su religión y se olvidó hasta de sus costumbres".

Como un nuevo poeta de la "negritud" emerge Achille Mbembe, uno de los teóricos más relevantes de los estudios postcoloniales, para trazar la trayectoria histórica de construcción y destrucción de lo "negro" desde la época colonial hasta la globalización neoliberal actual. Nacido en Camerún, Mbembe ha sido profesor en las universidades de Columbia y de Pennsylvania y, en la actualidad, imparte Historia y Política en el Wits Institute for Social and Economic Research (WISER) de la Universidad Witwatersrand de Johannesburgo.

Mbembe había llamado la atención de la Academia con sus provocativos ensayos De la post-colonie: essai sur l'imagination politique dans l'Afrique contemporaine y Sortir de la Grande Nuit. Essai sur l'Afrique décolonisée, La Découverte, escritos en la primera década del presente siglo, y en los que desgranaba un poderoso aparato conceptual, que confluye en su nuevo "libro río", Crítica de la Razón $\mathrm{Ne}$ gra. Ensayo sobre el racismo contemporáneo. En éste, reflexiona sobre la alteridad, sobre el origen del concepto negro, que vincula a la historia del capitalismo, y sobre lo que denomina el "devenir negro del mundo".

Pese a que el esclavismo, las plantaciones y el colonialismo fueron verdaderos laboratorios de experimentación social, en las narrativas sobre el nacimiento y evolución de la civilización occidental se ignora la historia de la colonización, en unos casos; y en otros, se presenta como la historia de la pacificación, de la puesta en valor de territorios vacíos y de la creación de instituciones, y sus costes sociales son percibidos como la "corrupción de una gran idea", sin aludir a la brutalidad de los métodos de predación, la parte maldita de la colonia, como diría Frantz Fanon.

Apoyándose en Edward Said, Mbembe se había propuesto la enorme tarea de reconstruir la prosa colonial y subrayar su potencia fabuladora. Se trataba de investigar el dilema del pensamiento ético europeo, que intentaba armonizar la fe en el hombre en occidente con el desprecio por la vida, el trabajo y el mundo de significaciones del colonizado. Mbembe huye de las grandes narrativas que han tratado de explicar las causas de los conflictos armados africanos y sus dinámicas invocando a la identidad, los recursos naturales, la pobreza o los estados fallidos. Para explicar la violencia, 
argumenta, hay que unir tres procesos inseparables, el poder, la violencia y la acumulación, lo que implica concebir lo Político como una relación de dominación, en la línea Foucaultiana de "relaciones de poder", o "Gubernamentalidad" en sentido extenso. Estas relaciones abarcan todos los ámbitos e instituciones sociales que permiten el ejercicio de un poder cuyo objeto es la población, sus instrumentos los dispositivos de seguridad y su discurso la economía política. El uso de la coerción en la colonia y en la postcolonia, escribe Mbembe, está ligado al ejercicio del poder, es una condición de la dominación política para confiscar el resultado de la acumulación.

La idea de biopoder de Michel Foucault ("dominio de la vida sobre el que el poder ha establecido su control") y de alteridad de Hanna Arendt, le llevan a definir el racismo como tecnología que permite el ejercicio del biopoder, "el viejo derecho soberano de matar". Frente al concepto convencional de soberanía que la sitúa en las fronteras del Estado-nación, en el seno de las instituciones situadas bajo autoridad estatal, Mbembe propone repensarla como "la instrumentalización generalizada de la existencia humana y la destrucción material de cuerpos y poblaciones humanas". La colonia ejemplifica, a su juicio, la noción de soberanía como estado de excepción, y de lugar donde el poder ejerce su autoridad mediante el uso de la violencia, e inserta la "economía de la muerte", es decir, el derecho a decidir sobre la vida de los gobernados. En la colonia, el poder se ejerce al margen de la ley, porque no está organizada como Estado y la habitan "salvajes". El derecho soberano de matar, concluye Mbembe, no está sometido a ninguna regla legal e institucional, y la guerra colonial no se considera una actividad legalmente codificada.

La segunda piedra angular de su discurso es la idea de "gobierno privado indirecto", forma inédita de "gubernamentalidad" que remite a los dispositivos creados para regular la conducta de los individuos, que surge en un contexto de gran desabastecimiento, violencia generalizada y desterritorialización, y es el resultado de una profunda reestructuración de las relaciones entre el individuo y la comunidad, entre los regímenes de la violencia, los de la propiedad y el orden tributario.

De otro lado, argumenta que en paralelo al fenómeno de "adelgazamiento" estatal de las economías neoliberales, en África se han transferido a manos privadas empresas esta- tales y servicios públicos, sobre la base de la mayor eficiencia del mercado. En un contexto caracterizado por la desregulación mundial de los mercados y los movimientos de capitales, se han privatizado los medios del poder coactivo. La soberanía y las funciones públicas son ejercidas por operadores privados y con fines lucrativos, dando lugar a la aparición de nuevas instituciones encargadas de gestionar la violencia. El poder se desdobla y se difuminan las fronteras entre lo público y lo privado. Se trata de un modelo político en el que el Estado no es la única instancia que provee seguridad, bienestar y representación de la población "nacional" en un territorio.

En Sortir de la grande nuit, Mbembe se interroga acerca de lo que supuso la descolonización y la teoría postcolonial para la "comunidad descolonizada", para entender la colonización desde el presente, como un proceso en muchos aspectos inacabado, y punto de inflexión entre el pasado y multitud de futuros posibles. Para salir de "la larga noche del mundo africano postcolonial", expresión que empleó Fanon para referirse al periodo colonial y a la necesidad de la emancipación, Mbembe subraya que los estados africanos deben escapar de la nueva colonización implantada por las instituciones financieras internacionales, y recuperar la legitimidad y la soberanía. El desarrollo económico en África exige orden político y estabilidad, lo que implica configurar un Estado y unas instituciones sociales capaces de llevar a cabo una transformación económica y social, apoyados en un sistema fiscal que garantice los fondos necesarios para promover el desarrollo, y en una fuerte capacidad regulatoria.

Como se decía más arriba, en su ensayo, Crítica de la razón negra, confluyen los distintos conceptos elaborados a lo largo de su agenda de investigación para glosar la "vertiginosa" biografía de África, "ese duplicado del mundo", que Mbembe articula en tres etapas. La primera se identifica con el saqueo perpetrado durante los siglos XV a XIX, mediante la conversión de los africanos en mercancías y el robo de sus apellidos y su lengua. La segunda, entre finales del siglo XVIII y el final del apartheid, viene marcada por innumerables conflictos y reivindicaciones, y en la que los Negros comienzan a articular un lenguaje propio y se reivindican como sujetos plenos en el mundo viviente. La tercera se inicia a principios del siglo XXI, y se caracteriza por 
la expansión planetaria de los mercados y su presión sobre los recursos naturales y la vida humana, la privatización del mundo bajo la hegemonía neoliberal y la conexión creciente entre las finanzas, el complejo militar y las tecnologías electrónicas y digitales.

Mbembe arremete contra la idea de raza y subraya que el término negro es una noción cuyos múltiples significados han cambiado a lo largo de la historia, pero, que, en todo caso, y como sugería Fanon, es una invención del Blanco. La palabra "negro" es el resultado de un proceso de atribución, de "racialización", un producto de la función "genética" del capitalismo. El esclavo de origen africano en América, dice Mbembe, es una figura singular del Negro que logra universalizarse como elemento clave de un modo de acumulación a escala mundial. El "devenir negro del mundo" es el momento en que no se puede distinguir entre el ser humano, la cosa y la mercancía.

Mbembe realiza un ejercicio ético, y hasta poético, de reconstruir la memoria y proyectar un futuro común. A tal fin, invoca a autores como Aimé Césaire y Frantz Fanon $\mathrm{y}$, más allá de estos al poeta de la isla de Santa Lucía, Derek Walcott, y al cubano Nicolás Guillén. Al evocar la violencia de la conquista colonial recurre al Discurso sobre el colonialismo, en el que Césaire niega la identificación entre Colonización y civilización, que ha forjado el discurso hipócrita del colonizador. Con reminiscencias kantianas, Césaire se preguntaba ¿qué es, en principio, la colonización?, para responder sin paliativos: "Ecuación deshonesta, hija del apetito, de diversas codicias, y de la fuerza". Para analizar la actualidad de las prácticas coloniales/imperiales, recuerda la percepción de la vida del colonizado como una lucha permanente contra una muerte omnipresente, que describiera Fanon, ¿cómo releer Cesaire sin Fanon?, se pregunta Mbembe.

El tiempo presente se caracteriza, según Mbembe, por la contracción del espacio y por la repoblación de la tierra, lo que se traduce en un aumento de la segregación social y enormes olas migratorias a nivel planetario. Proliferan las fronteras y se recurre al "fantasma del enemigo" para normalizar el estado de excepción a escala mundial. No existen trabajadores, sino nómadas del trabajo, sentencia Mbembe, y una población superflua, expulsada de los sistemas políticos y económicos.
Para explicar la "crisis" de los refugiados y la gestión de la población superflua, Mbembe articula a Foucault con la mirada de Fanon, al que relee, como hiciera Wallerstein, con la mirada del siglo XXI, y se vale de dos conceptos íntimamente relacionados desarrollados en anteriores trabajos: "necropolítica" y "necroeconomía". Habla de necroeconomía en el sentido de que una de las funciones del capitalismo actual es producir a gran escala una población excedente, que ya no tiene necesidad de explotar, pero que hay que gestionar. Y, en clara referencia a Bauman, sostiene que el capitalismo expone a estos "residuos" a todo tipo de peligros o los aísla y encierra en zonas de control. La necropolítica sería el trasunto político de esta forma de violencia del capitalismo contemporáneo.

Las lógicas de la distribución de la violencia a escala planetaria y la amplia operación de depreciación de fuerzas productivas no escapan a ninguna región del mundo. El caso griego ejemplifica, a su juicio, la aplicación de la idea de "gobierno privado indirecto", elaborada en los años 90, a la actualidad, en tanto forma de gestión de la deuda, que desarrolla en países dependientes económicamente una tecnología de la expropiación al margen de las instituciones, privatizando lo común, responsabilizando de los males a los individuos y delegando el poder soberano a instancias no-democráticas. A escala mundial, el gobierno privado indirecto es un movimiento de las élites que tiene su origen en las profundas transformaciones experimentadas por el capitalismo en los años 70 del siglo XX y que aspira, en última instancia, a abolir lo político, y a desmantelar todo espacio y todo vínculo presente o intergeneracional.

Pese a todo, Mbembe entona un "réquiem por el esclavo" y mira a un horizonte de emancipación en el que haya cristalizado una nueva forma de humanismo, que permitiría salir de la gran noche postcolonial. Y en ese ideal de "elevación hacia la humanidad" en un mundo liberado del lastre de la raza, se encuentra de nuevo con Fanon y su "proyecto de crecimiento colectivo en humanidad". Mbembe defiende la creación "de un mundo común, de una humanidad común, de una historia y de un futuro que podemos ofrecer y compartir", un "todo-mundo", por utilizar la feliz expresión de Eduard Glissant. Pero el futuro de ese mundo no está asegurado a menos que la humanidad se dedique a construir lo que el propio Mbembe denomina las "re- 
servas de la vida", y las instituciones sociales a luchar contra la muerte del ser humano y acabar con la corrupción.

Salir de la "minoría de edad" solo es posible mediante un cambio operado por el hom- bre sobre sí mismo, y Fanon, como escribía Jean Paul Sartre, mostró el camino a los combatientes cuando afirmó: "Desde hace tiempo, el cielo estrellado, que dejaba jadeante a Kant, nos ha confiado sus secretos".

\section{Referencias}

López, Fernando. 2012. Le développement en perspective historique: le regard néoinstitutionnaliste, la pensée postcoloniale et les "mauvais samaritains. Economie appliquée 64 (4), pp.5-41.

Mbembe, Achille, 2000. De la post-colonie: essai sur l'imagination politique dans l'Afrique contemporaine, Karthala, Paris,

Mbembe, Achille, 2007. Poder, violencia y acumulación, En Fernando López Castellano (comp.), Desarrollo: crónica de un desafio permanente, Periferias/Universidad de Granada.

Mbembe, Achille. 2010. Sortir de la Grande Nuit. Essai sur l'Afrique décolonisée, La Découverte, París.

Mbembe, Achille. 2011. Necropolítica. Editorial Melusina, Madrid.

Mbembe, Achille. 2016. Crítica de la Razón Negra. Ensayo sobre el racismo contemporáneo, NED ediciones, Barcelona. 